\title{
Reutilização de madeira de paletes no projeto de uma linha de produtos para hall de entrada
}

\author{
Reuse of pallet wood in the project \\ of a product line for entrance hall
}

\author{
Caroline Reichow Tuchtenhagen ${ }^{[1]}$, Mariana Piccoli $^{[2]}$
}

\begin{abstract}
Resumo: A conscientização sobre o impacto ambiental está gerando uma nova orientação para o design como, por exemplo, o reaproveitamento de partes descartadas pela indústria. O presente artigo apresenta um recorte do trabalho de conclusão de curso (TCC), que teve como objetivo de pesquisa desenvolver uma linha de produtos reutilizando a madeira do palete, do tipo descartável. Para isso foram estudados conceitos de ecodesign, reutilização e o próprio material o palete. A metodologia projetual se baseou no Duplo Diamante, com ferramentas de Gui Bonsiepe. Como resultado, foi desenvolvida uma linha de quatro produtos que compõem o mobiliário para um hall de entrada. Concluiu-se que a construção de produtos com a madeira de paletes descartáveis é viável, podendo ser realizada por qualquer pessoa.
\end{abstract}

Palavras-chave: Design de Produto. Ecodesign. Reutilização. Palete.

Abstract: The awareness of environmental impact is generating a new orientation for design, for example, the reuse of parts discarded by the industry. This article presents an excerpt from the course completion work (TCC), which aimed to develop a product line reusing the wood from the pallet, the disposable type. For this, concepts of ecodesign, reuse and the material, the pallet, were studied. The design methodology was based on the Double Diamond, with tools by Gui Bonsiepe. As a result, a line of four products that make up the furniture for a lobby was developed. It was concluded that the construction of products with wood from disposable pallets is feasible and can be performed by anyone.

Keywords: Product Design. Ecodesign. Reuse. Pallet. 


\section{INTRODUÇÃO}

Nas últimas décadas a conscientização sobre o impacto ambiental está levando a sociedade a discutir e se reorientar em um novo comportamento social, buscando por produtos e serviços desenvolvidos com tecnologias limpas (MANZINI, VEZZOLI, 2002). O reaproveitamento de materiais descartados pelas fábricas gerou uma nova orientação para o campo do design. Ao longo da história, a reutilização de produtos tem motivações variadas, porém a partir da década de 1960, o motivo da reutilização tem sido a preocupação com o meio ambiente.

A indústria atual gera muitos resíduos que não são interessantes para a utilização em novos produtos, são sobras. Outros, são materiais utilizados no transporte - como é o caso dos paletes, resíduo foco deste trabalho - que são integralmente descartados. Os paletes são estrados de madeira, plástico ou metal, destinados a suportar cargas pesadas e ajudam a agilizar o carregamento de produtos em geral, facilitando também a movimentação, o transporte e a armazenagem. Porém, muitos destes paletes, principalmente os de madeira, são frágeis e por essa razão não os utilizam novamente, sendo assim muitas vezes descartados de maneira inapropriada pela indústria.

A reutilização do palete para outras funções e para o desenvolvimento de novos produtos já vem sendo explorada por profissionais de diversas áreas. Exemplos como floreiras, bancos, mesas, sofás de rua, são algumas das propostas que podem ser vistos mais frequentemente através de movimentos de "faça você mesmo".

Dada a observação do cenário contemporâneo, que envolve temas de importância para o design e o meio ambiente, a questão da pesquisa foi: "Como reutilizar a madeira de palete que é descartada por uma indústria local, para desenvolver uma linha de produtos?" Sendo o objetivo geral deste trabalho desenvolver uma linha de produtos reutilizando madeira de paletes descartáveis, a partir de conceitos como ecodesign e reutilização. 
O presente artigo é um resumo do trabalho de conclusão de curso (TCC) que apresentara parte da fundamentação teórica, da geração de alternativas e dos resultados finais da linha de produtos para um hall de entrada.

\section{O ECODESIGN}

Com a revolução industrial, a produção em grande escala se proliferou, o design surge então como um dos instrumentos determinantes no impacto ambiental. Nos anos 60 e 70, foram criadas várias metodologias abordando os problemas ambientais no design, tais como Design para o Ambiente (Design for Environment - DFE), Design Verde (Green Design - GD), Design com Consciência Ambiental (Environmentally Conscious Design - ECD) e Ecodesign, todas elas têm em vista o mesmo objetivo final, que é, de maneira resumida, a minimização do impacto ambiental de um determinado produto ou processo (GOMES, 2011).

Ecodesign, Design Verde ou Design Ecológico, para Pazmino (2007), surge do encontro entre o meio ambiente e o exercício de projetar, desenvolvendo assim um produto consideravelmente competitivo no mercado e ecologicamente correto, minimizando os impactos ambientais.

Para Kazazian (2005) o ecodesign também pode ser chamado de "eco concepção", essa abordagem consiste em reduzir os impactos de um produto, ao mesmo tempo em que mantém sua qualidade de uso, como funcionalidade e desempenho, para melhorar a qualidade de vida dos usuários.

O ecodesign para Manzini e Vezzoli (2016) é uma metodologia de projeto orientada por critérios ecológicos. Esta metodologia se preocupa com a sustentabilidade e o ciclo de vida dos produtos, procurando promover um sistema produtivo que seja capaz de responder à procura social e ao bem-estar, reduzindo a quantidade de uso dos recursos naturais em comparação com os atuais. 
Alguns dos princípios ecológicos citados por Manzini e Vezzoli (2016) no momento do projeto do produto, podem ser observados na lista abaixo:

- Escolha de materiais e processos: utilização de materiais renováveis, não tóxicos, biodegradáveis, reciclados ou que provenham de refugos, utilizando processo de baixo impacto ambiental;

- Fontes energéticas: escolha de fontes energéticas renováveis, locais e que minimizem as emissões nocivas no momento de produção, distribuição e uso;

- Durabilidade: desenvolvimento do projeto de produtos com maior vida útil, ou seja, que funcionem melhor e por mais tempo.

- Adaptabilidade: Desenvolvimento do projeto de produtos reconfiguráveis ou multifuncionais, com fácil substituição de peças.

- Reutilização: reaproveitamento de produtos para desenvolvimento de novos e projeto de produto pensando na reutilização após uso.

Na Figura 1 podem ser observados alguns exemplos da aplicação desses princípios de ecodesign. Dentre eles, o da reutilização, que será o foco principal do trabalho.

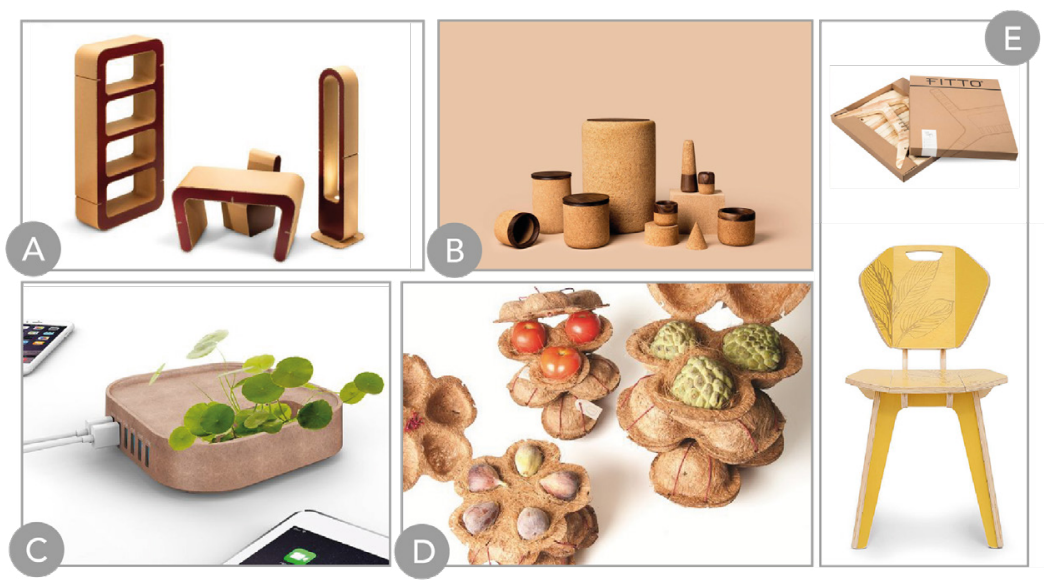

Figura 1: Exemplos de aplicação em Ecodesign. A) Móveis para escritórios feitos de papelão reciclado; $B$ ) Utensílios domésticos feitos manualmente com madeira e cortiça; C) Múltiplo USB permite conectar 6 dispositivos e cultivar um mini jardim; $D$ ) Embalagens feitas a partir da palha do coco; E) Cadeira pintada com corantes naturais e que possui embalagem compacta. 
Para esta pesquisa cabe ao designer a importante tarefa de reutilizar um objeto descartado, reaplicando em outra função, acrescentando a ele valores estéticos, econômicos e principalmente ecológicos.

\section{A REUTILIZAÇÃo}

É importante esclarecer nesse trabalho que há uma grande diferença entre o conceito de reutilização e reciclagem, pois muitas vezes estes conceitos são confundidos pela similitude de seus objetivos. Segundo Barbero e Cozzo (2009):

(...) os conceitos de reciclagem e reutilização diferenciamse pela natureza dos produtos a que dão origem. Enquanto a reciclagem prevê a transformação e reutilização do material, ou materiais, do objeto que é reciclado, a reutilização volta a dar uso ao próprio objeto, procedendo a alterações formais e estruturais, mas sem produzir alterações químicas ou físicas. Em termos de duração, no primeiro caso são os materiais que perduram no tempo para além da duração do produto, e no segundo caso é o próprio objeto (BARBERO; COZZO, 2009, p. 24).

Assim, de forma a diferenciar esses conceitos na prática, são expostos a seguir exemplos de produtos feitos a partir de um mesmo material: o plástico. Quando reutilizado, o plástico dá origem a sapateiras, estantes, luminárias, porta alimentos, entre tantos outros produtos (figura 2, exemplo A). Já por meio da reciclagem ele é reinserido no processo produtivo como matéria-prima, e transforma-se novamente em novos produtos de diversas formas e tamanhos. Um exemplo é a linha de produtos da ecoBirdy, uma marca de design artesanal pensada para crianças, suas peças são feitas a partir de resíduos plásticos $100 \%$ reciclados de brinquedos não utilizados (figura 2, exemplo B).

Em se tratando da valorização dos resíduos, a reutilização é preferível à reciclagem, "em termos ambientais, geralmente é preferível reutilizar um produto, ou uma parte dele, em vez de reciclá-lo ou incinerar seus materiais (para não falar na hipótese de simplesmente colocá-lo no lixo)" (MANZINI, VEZZOLI, 2016, p.114). 


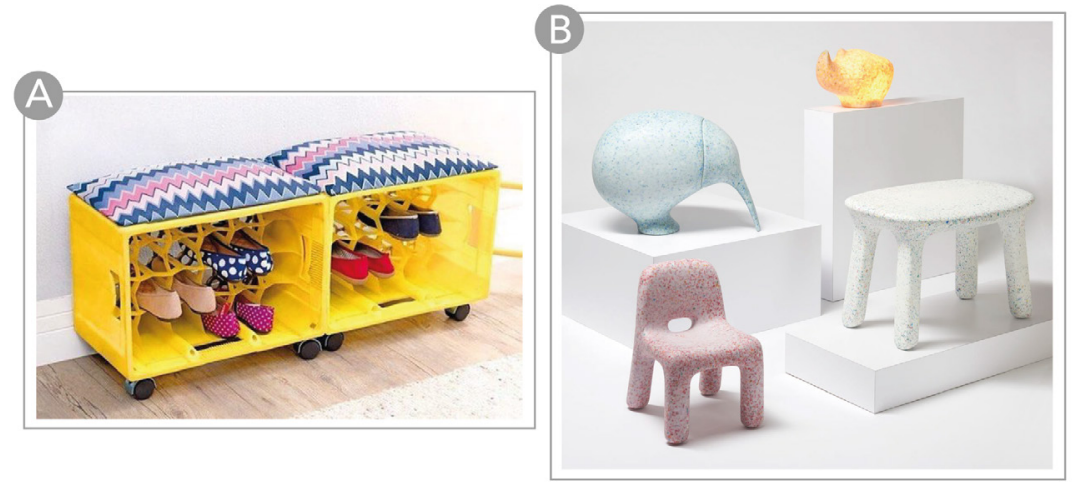

Na Figura 3 pode-se observar a ordem de prioridades das ações utilizadas para lidar com os resíduos, considerando os potenciais benefícios em termos de energia, materiais e impactos ambientais. As medidas mais eficazes e com maior potencial de retorno financeiro, estão localizadas na parte superior, são conhecidas como os 3Rs, reduzir, reutilizar e reciclar.

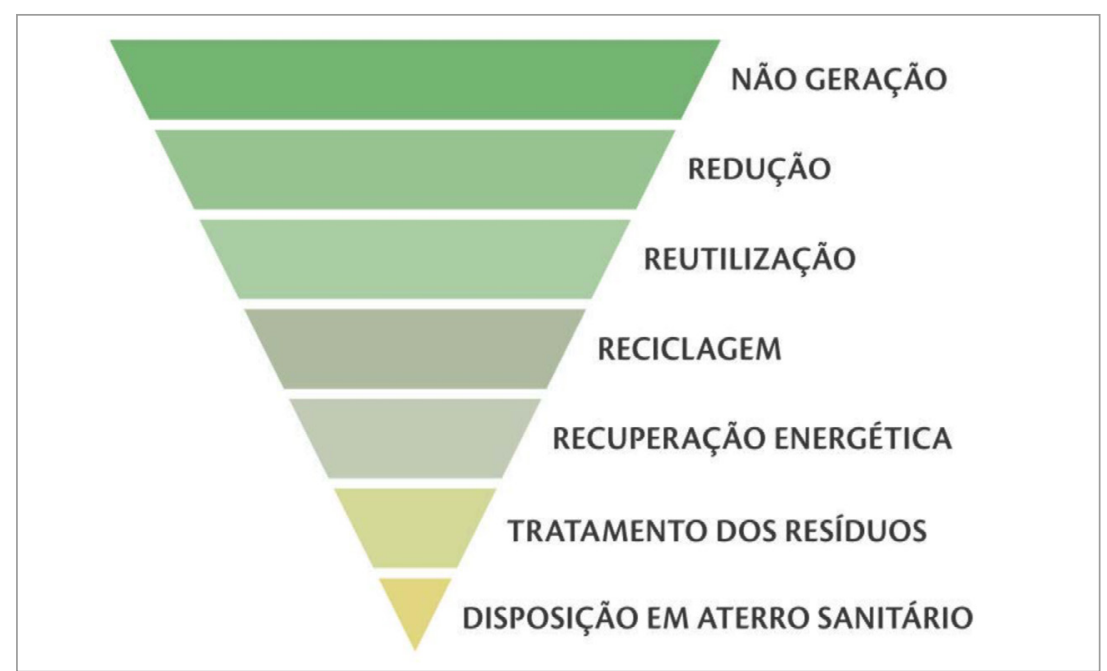

Há uma série de tipologias distintas no que diz respeito à reutilização. Existe as atividades de ciclo fechado, como a reutilização direta e a remanufatura, e as atividades de ciclo aberto, que inclui o repurposing (redirecionar) ou upcycling.
Figura 2: Exemplo de reutilização e Reciclagem do plástico.

Figura 3: A hierarquia dos resíduos. 
A reutilização em ciclo fechado é quando um objeto é reutilizado na mesma função que a utilização inicial. Na reutilização direta o objeto não sofre nenhum processo de recondicionamento especial, ele é simplesmente reutilizado para a mesma aplicação, um exemplo são as garrafas de vidro de refrigerantes e de vinho. Já a remanufatura é um processo industrial e geralmente é aplicada em produtos mais complexos, onde são restaurados para torná-los novos, um exemplo são as máquinas de xerox (GOMES, 2011).

Já a reutilização em ciclo aberto existe quando o objeto adquire uma nova função, diferente daquela para o qual foi criado. Existe a reutilização prevista em que a segunda vida do produto com outra função pode já ter sido prevista pelo designer, onde o objeto reutilizado não é alterado ou não sofre alterações, ou seja, não perde a identidade original (GOMES, 2011). Porém, na maioria dos casos a reutilização em ciclo aberto é totalmente imprevista, chamada de reutilização em outra função (repurposing), cabe a quem reutilizar o objeto a capacidade de identificar novas aplicações e funções que não foram pensadas inicialmente.

Para esta pesquisa foi adotado a reutilização em ciclo aberto com ênfase no repurposing (redirecionar), onde o palete como objeto principal desta pesquisa, sofrerá alterações significativas para se adequar à nova função.

\section{O PALETE}

O palete é um estrado de madeira, de plástico ou até mesmo de metal, que ajuda no manuseio, armazenagem e suporte de cargas. Com a ajuda de empilhadeiras é possível utilizar o palete para carregar grande quantidade de peso, podendo assim, ser um aliado da produtividade e agilidade da logística de uma empresa.

Não foi encontrado nenhum registro histórico sobre o surgimento do palete, contudo, sua forma moderna data da metade do século $X X$, mesma data da invenção da empilhadeira, onde era muito utilizado no transporte marítimo, ajudando na carga e descarga dos produtos (HAAS, 2018). 
Existem vários modelos de paletes no mercado, os mais utilizados para armazenagem no Brasil são os paletes PBR, paletes comuns, paletes de plástico e paletes descartáveis, mas ainda existem os paletes de metal e de papel.

O palete utilizado para o desenvolvimento desta pesquisa foi o palete descartável (figura 04). Esse palete é muito usado na indústria, pois ele tem baixo peso e menor custo, em relação aos demais, é feito com madeiras diferentes - Pinus, eucalipto, eucalipto precoce - e projetados de acordo com as peças que serão movimentadas, não há uma padronização, por está razão ele é descartado após o uso, não sendo possível uma segunda utilização (FABRIMETAL, 2017).
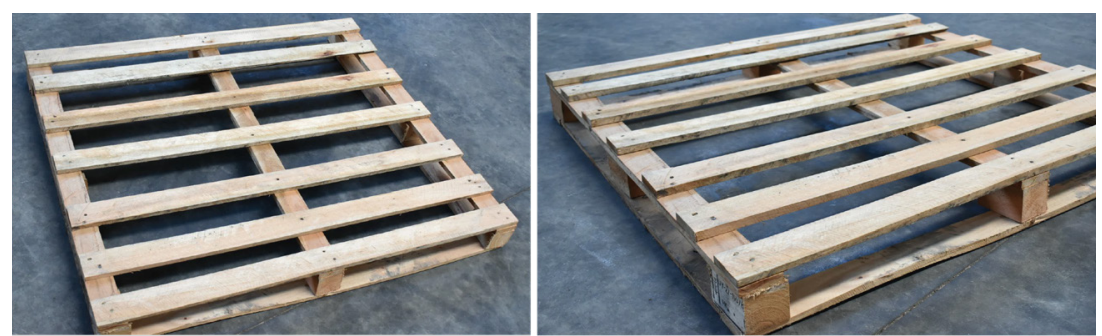

Figura 4: Palete descartável.

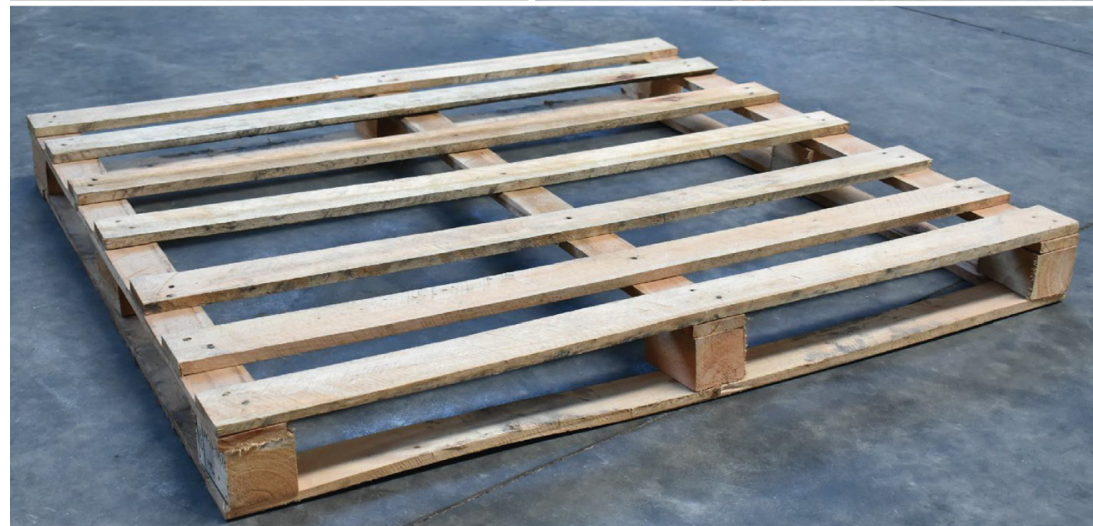

Para esta pesquisa cabe ao designer a importante tarefa de reutilizar um objeto descartado, reaplicando em outra função, acrescentando a ele valores estéticos, econômicos e principalmente ecológicos. 


\section{METODOLOGIA}

A metodologia projetual utilizada como base para este trabaIho foi a do Duplo Diamante, desenvolvida pela Design Council (2004), com ferramentas/análises de Gui Bonsiepe (1984). Esta metodologia foi dividida em quatro etapas, que são: descobrir, definir, desenvolver e entregar.

Figura 5: Metodologia de Projeto

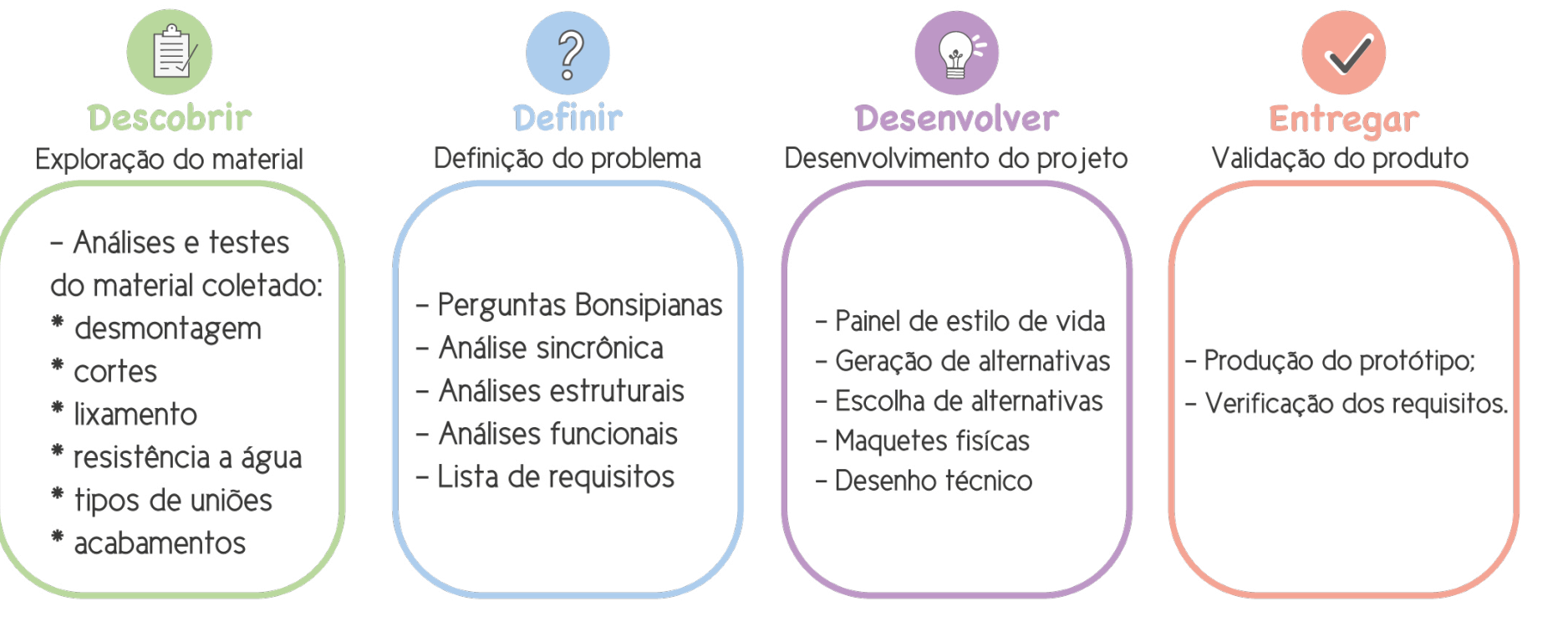

Na primeira etapa, a fase descobrir, foram abordados assuntos relativos à análise e testes do material coletado. A segunda etapa, a fase definir, abordou questões relativas ao tema do produto, o conceito, os requisitos que devem ter/ não ter, o que já existe no mercado e como é a estrutura e função destes produtos que já existem.

Na terceira etapa, a fase desenvolver, apresentou as gerações de alternativas, inspirados no painel de estilo de vida e nos testes já realizados com o material. Logo após a escoIha das melhores alternativas apresentou-se a maquete em tamanho reduzido. A última fase da metodologia de projeto, abordou os resultados do produto. 
É importante destacar que um dos objetivos do trabalho é ser um projeto de design aberto, ou seja, que possa ser divulgado, compartilhado e reproduzido por qualquer pessoa. Esse fato é importante para incentivar e disseminar propostas de reutilização de paletes descartados, valorizando o material. Assim, a geração de alternativas e os processos construtivos foram baseados no uso de ferramentas simples, possíveis de se ter em casa e de fácil manuseio.

\section{DESENVOLVIMENTO - GERAÇÃO DE ALTERNATIVAS}

Através dos testes e análises realizados com o material e análises sincrónicas, estruturais e funcionais, perguntas bonsipianas e lista de requisitos, foi possível chegar em uma lista de possíveis produtos a serem desenvolvidos com a madeira do palete. Dessa lista de produtos foram escolhidos produtos que poderiam compor um hall de entrada, levando em consideração a atual situação de pandemia, em que as pessoas precisam ao entrar em casa deixar suas coisas na entrada da casa para não contamina-la por inteira.

Os produtos escolhidos foram: o banco/sapateira, o cabideiro de parede, o suporte para vaso de planta e a luminária, formando assim uma linha de quatro produtos. Para cada produto foram geradas de 2 a 5 alternativas (figura 6). As alternativas escolhidas foram, o banco/sapateira ripadinho com linhas retas, o cabideiro de parede vertical com linhas diagonais, o suporte para vaso com quatro pés e a arandela de parede.

Figura 6: Geração de alternativas. Fonte: acervo da autora.
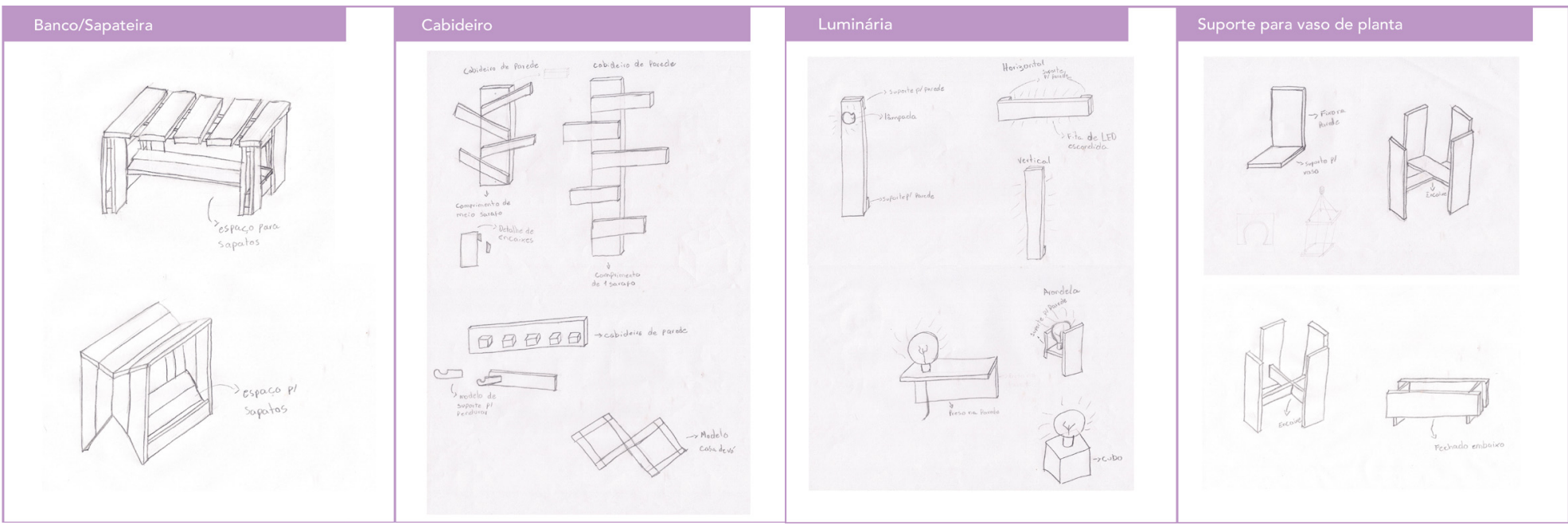
Como a escolha das alternativas foram feitas as maquetes em madeira balsa em tamanho reduzido de 1:7 para uma melhor visualização de como ficaria cada peça e como seriam feito os encaixes e junções (figura 7).

Figura 7: Maquetes em tamanho reduzido. Fonte: acervo da autora.

Banco/Sapateira

Apesar dos produtos terem uma coerência entre si, eles não estão limitados a somente um lugar possível de ser colocado na casa ou de serem sempre colocados juntos, eles poderão ser utilizados separadamente em diferentes ambientes.

\section{RESULTADOS ALCANÇADOS}

Depois de definida uma alternativa para cada produto da linha, iniciou-se a produção dos protótipos dos produtos finais. Para a produção dos protótipos foram levados em conta os testes realizados com o material, por essa razão os paletes 
utilizados para a construção dos produtos foram os mesmos utilizados no teste de desmontagem.

Assim sendo, para os cortes foi utilizada a serra tico-tico, para o lixamento a lixadeira elétrica manual com utilização de lixas $n^{\circ} 120$ e $n^{\circ} 220$, para a montagem foram utilizados parafusos com furação prévia e encaixe simples.

Como acabamento foi escolhido o Lasur incolor, por ter apresentado um melhor acabamento em relação a cor, pois ele não altera a cor da madeira, apenas realça os veios. Para esse projeto foi escolhido este acabamento pois o intuito era realçar a diferença de madeiras que o palete tinha.
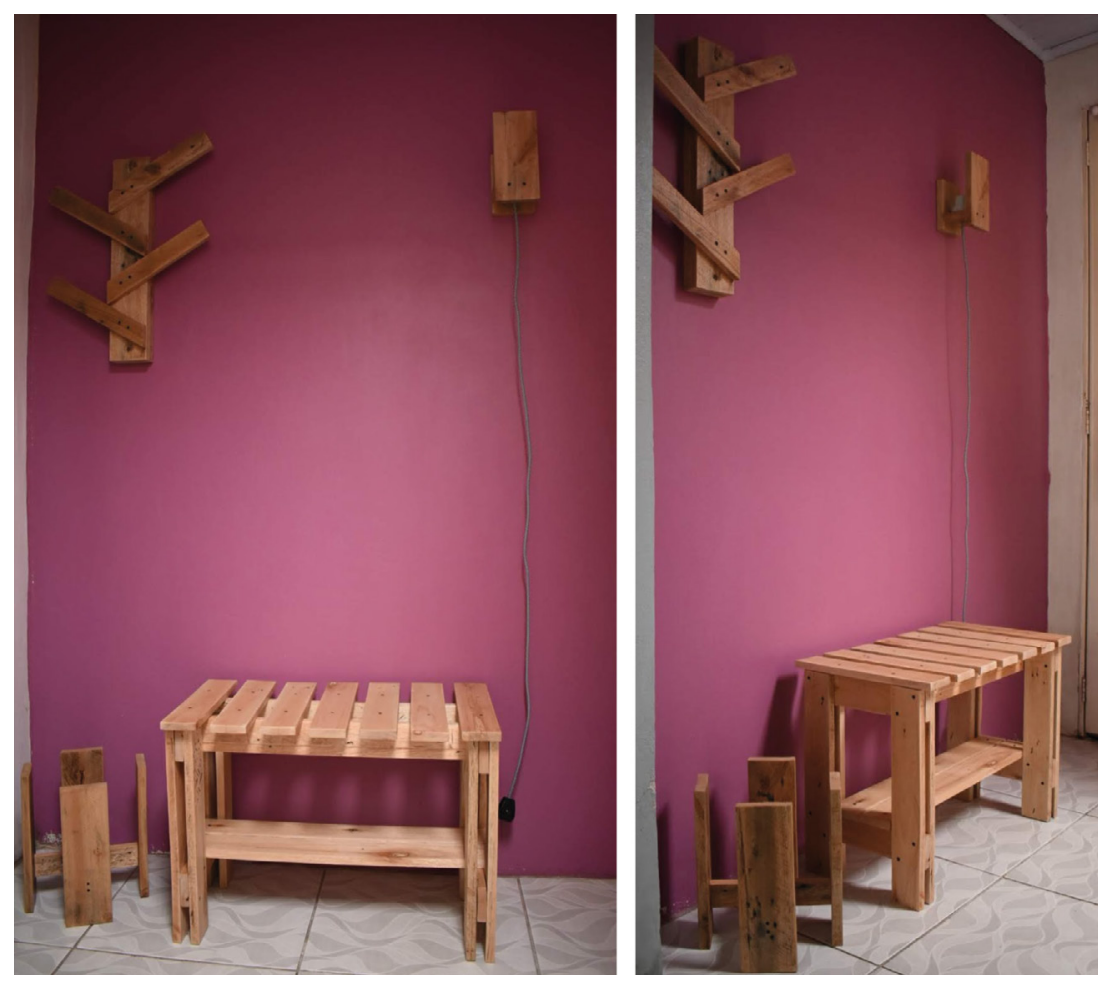

Figura 8: Produtos no hall de entrada. Fonte: acervo da autora.

Todo o processo de construção dos protótipos foi realizado por duas pessoas. Foi preciso um palete e meio para a construção da linha e levou em torno de 20 horas para serem concluídos todos os produtos. 
É importante destacar que as madeiras utilizadas foram madeiras com furos e com algumas imperfeições, realçando a estética do palete, as suas marcas e diferentes tipos de madeiras, assim obtendo um bom aproveitamento do material.

Nas imagens a seguir serão apresentados os resultados alcançados com a prototipagem de cada produto.
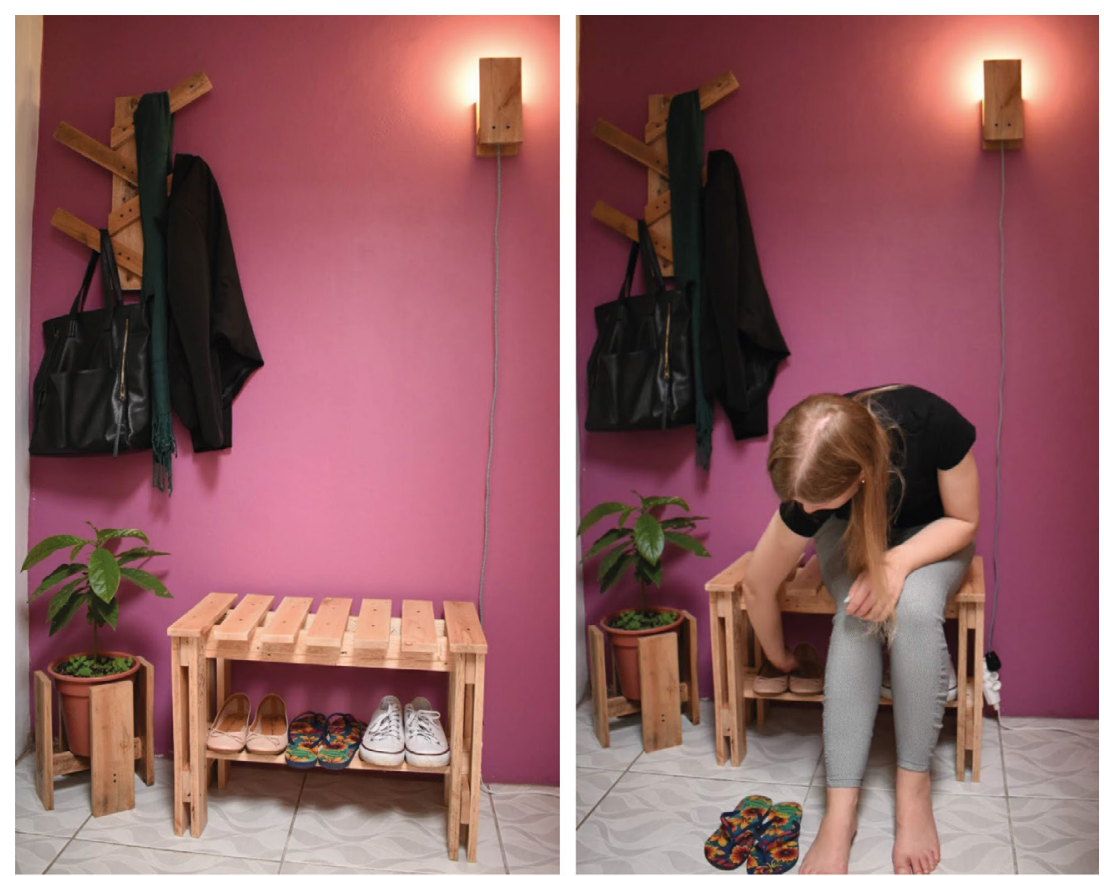

Figura 9: Produtos com objetos no hall de entrada. Acervo da autora.
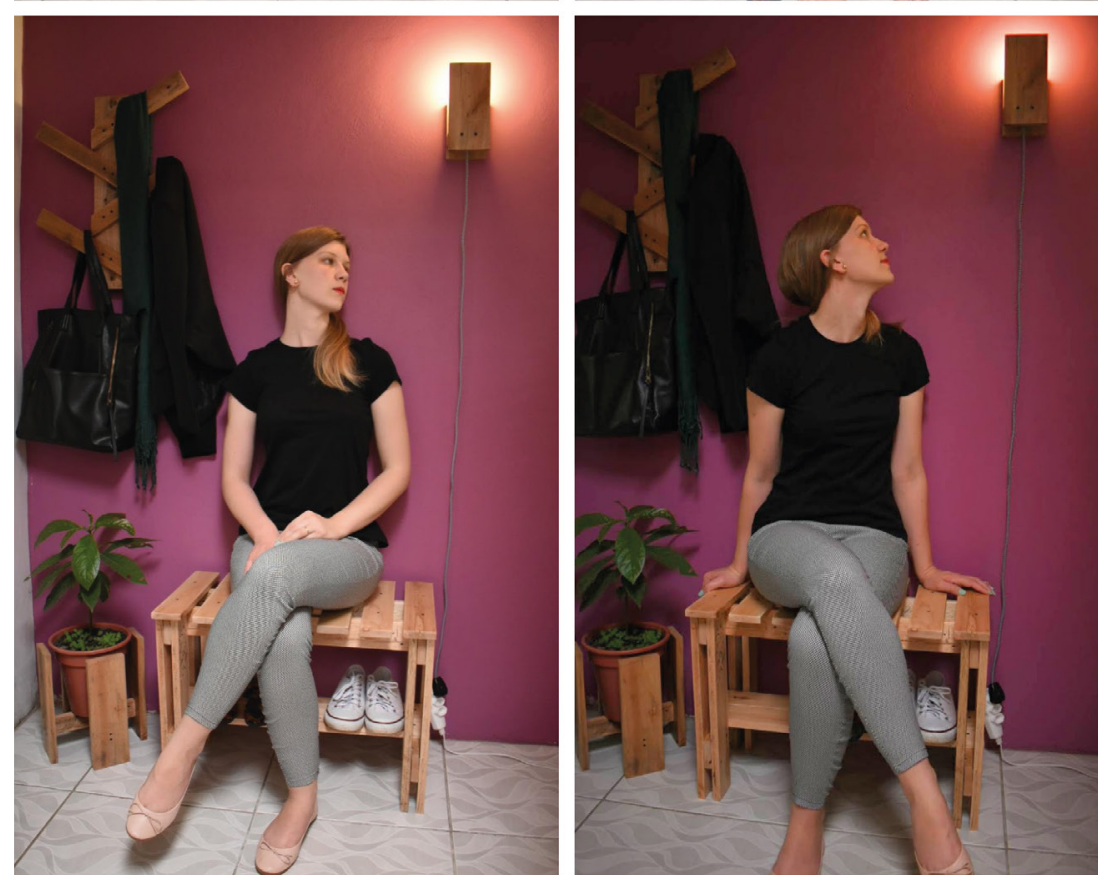
Com a execução dos protótipos foi possível certificar-se que a construção de produtos com a madeira de paletes descartáveis é viável. Podendo ser realizada por qualquer pessoa que saiba utilizar as ferramentas necessárias para sua confecção.

\section{CONSIDERAÇÕES FINAIS}

Ao final do trabalho constatou-se que o objetivo geral proposto, de desenvolver uma linha de produtos a partir da reutilização da madeira do palete descartável, foi atingido. Através dos estudos teóricos sobre ecodesign, reutilização e o material - o palete - foi possível entender melhor os tipos de princípios ecológicos e de reutilização.

A metodologia projetual desenvolvida para este projeto foi de grande importância para sistematizar o processo do desenvolvimento dos produtos. O intuito de ser um projeto aberto, os vários testes feitos com o material, as definições com as perguntas bonsipianas e a listas de requisitos, foram responsáveis por criar limitações ao projeto. Desta forma os produtos ficaram fáceis e possíveis de serem executados por qualquer pessoa que desejar construi-los.

Concluiu-se também que as marcas que o palete possui, faz com que a linha de produtos se diferencie, por exemplo, de uma linha de produtos feitos com madeira não reutilizada, criando uma estética diferenciada para cada novo produto construído.

E por fim, conclui-se que o ecodesign não deve ser considerado um ato artesanal produzido a partir de sucata ou reciclagem, mas como uma concepção presente em cada designer, que no ato de projetar leva em consideração os aspectos de impactos ambientais de um produto em todo o seu ciclo de vida. 


\section{REFERÊNCIAS BIBLIOGRÁFICAS}

BARBERO, Silvia; COZZO, Brunella.

Ecodesign. h.f.ullmann, 2009.

BONSIEPE, Gui (org); KELLNER, Petra; POESSNECKER, Holger. Metodologia experimental: Desenho industrial.

1.ed. Brasília: CNPq/ coordenação editorial, 1984.

Design Council. Qual é a estrutura para inovação?

Diamante Duplo evoluído do Design. 2015 < https://

www.designcouncil.org.uk/news-opinion/what-

framework- innovation-design-councils-evolved-

double-diamond> Acesso em: 27 set. 2019.

FABRIMETAL, armazenagem. Tipos de paletes

para armazenagem. 2017. Disponível em: <http://

www.fabrimetalarmazenagem.com.br/blog/

tipos-de-paletes-para-armazenagem/?gclid=Cj0

KCQjw5rbsBRCFARIsAGEYRwfnEHsHAygZTWFhT-

ljRFiMUi3fF4j14pK73SnZ2LGAX81 Fvwb2vkAaAmUgEALw_

wcB> Acesso em: 16 nov. 2019.

GOMES, Daniel. $\mathbf{R}$ em Design: a reutilização

aplicada ao design. Dissertação - Mestrado em

Design Industrial pela Faculdade de Engenharia da

Universidade do Porto (FEUP), Portugal, 2011.

HAAS, Madeiras. O que é palete e qual sua origem. 2018.

Disponível em: <https:// www.haasmadeiras.com.br/o-que-

e-palete-e-qual-a-sua-origem/> Acesso em: 18 nov. 2019.

KAZAZIAN, Thierry. Haverá a idade das coisas leves:

design e desenvolvimento sustentável. Senac, 2005.

MANZINI, EZo; VEZZOLI, Carlo. Desenvolvimento de

Produtos Sustentáveis: Os requisitos ambientais

dos produtos industriais. 1. ed. 4. reimp. São Paulo:

Editora da Universidade de São Paulo, 2016. 
OWDIN. EcoBirdy crée des meubles pour enfants faits à partir de vieux jouets en plastique. 2018.

Disponível em: https://owdin.live/2018/08/26/ecobirdycree-des- meubles-pour-enfants-faits-a-partir-devieux-jouets-en-plastique/. Acesso em 09 nov. 2020.

PAZMINO, Ana Verónica. Uma reflexão sobre Design Social, Eco Design e Design Sustentável. I Simpósio Brasileiro de Design Sustentável. Curitiba, 2007.

PICCOLI, Mariana. Reutilização de tubos de papelão: estudo de parâmetros técnicos visando aplicação no design de produtos. Dissertação (Mestrado) - Universidade Federal do Rio Grande do Sul, Escola de Engenharia, Programa de Pós-Graduação em Design, Porto Alegre, BR-RS, 2013.

PINTEREST. Banco sapateira de engradado de cerveja. 2020. Disponível em: https://br.pinterest.com/ pin/456763587188650175/ Acesso em: 09 nov. 2020.

PINTEREST. Reutilização de paletes. 2019a. Disponível em: <https://bit.ly/3GTGHkP>. Acesso em: 16 nov. 2019. 